\title{
70 anos da Aliança Nacional Libertadora (ANL)
}

ANITA LEOCADIA PRESTES*

\begin{abstract}
Resumo: O artigo examina a atuação da Aliança Nacional Libertadora - uma ampla frente formada, em 1935, por setores representativos da sociedade brasileira da época, mobilizados em torno da luta contra o avanço do integralismo no Brasil e do fascismo no cenário mundial, assim como contra a dominação imperialista e o latifúndio em nosso país.
\end{abstract}

Abstract: This article examines the operation of Aliança Nacional Libertadora (National Alliance for Freedom), a large organization formed in 1935 by representative sectors of the Brazilian society at the time. Its movements were directed against the advance of Integralism in Brazil and Fascism in the global scenario, and against imperialist domination and latifundium in Brazil.

Palavras-chave: Aliança Nacional Libertadora. PCB (Partido Comunista do Brasil). Antifascismo.

Key words: National Alliance for Freedom. Communist Party of Brazil. Anti-Fascism.

Há 70 anos, em 30 de março de 1935, tinha lugar, no teatro João Caetano, no Rio de Janeiro, o lançamento público da Aliança Nacional Libertadora (ANL). Era constituída uma ampla frente formada por setores representativos da sociedade brasileira da época, mobilizados em torno de quatro objetivos principais: luta contra o avanço do integralismo no Brasil e do fascismo no cenário mundial, e luta contra a dominação imperialista e o latifúndio em nosso país.

* Doutora em História Social pela Universidade Federal Fluminense (UFF), Niterói, Rio de Janeiro, Brasil, e professora de História do Brasil no Departamento de História da UFRJ. E.mail: anitaprestes@ifcs.ufrj.br

Estudos Ibero-Americanos. PUCRS, v. XXXI, n. 1, p. 101-120, junho 2005 


\section{Os antecedentes}

No início dos anos 30, nas palavras de E. Hobsbawm, a economia mundial havia mergulhado "na maior e mais dramática crise que conhecera desde a Revolução Industrial" (Hobsbawm, 1995, p. 43). Uma crise, cuja "extraordinária universalidade e profundidade" ninguém esperava e que

equivaleu a algo muito próximo do colapso da economia mundial, que agora aparecia apanhada num círculo vicioso, onde cada queda dos indicadores econômicos (fora o desemprego, que subia a alturas sempre mais astronômicas) reforçava o declínio em todos os outros (ibid., p. 96).

A chamada Grande Depressão, "o mais trágico episódio na história do capitalismo", teria como conseqüência inelutável a "destruição do liberalismo econômico por meio século" (ibid., p. 99). Estava em curso uma catástrofe que viria atingir o mundo como um todo, afetando os mais diferentes aspectos da vida humana. Ainda na avaliação de E. Hobsbawm: "O período de 1929-33 foi um abismo a partir do qual o retorno a 1913 tornou-se não apenas impossível, como impensável. O velho liberalismo estava morto, ou parecia condenado" (ibid., p. 111).

Estava-se diante do avanço não só das ideologias fascistas, como também dos movimentos fascistas, cuja ascensão ao poder principalmente na Alemanha lhes daria uma força e influência, que não teriam podido alcançar apenas como conseqüência da Grande Depressão (ibid., p. 133). A subida de Hitler ao poder, em janeiro de 1933, deixaria aquela década marcada pelo estigma do fascismo (ibid., cap. 4).

Logo a seguir, o incêndio do Reichstag ${ }^{1}$, em fevereiro de 1933 provocação montada pelos nazistas com o objetivo de justificar a repressão contra os comunistas -, quando o dirigente comunista búlgaro Jorge Dimitrov, juntamente com outros militantes comunistas, foi preso e submetido a rumoroso processo no Tribunal de Leipzig, alcançaria enorme repercussão no mundo inteiro e também no Brasil, o que pode ser comprovado pela leitura da imprensa da época. ${ }^{2}$

A campanha em defesa das vítimas do Processo de Leipzig viria a assumir proporções extraordinárias, mobilizando amplos setores da opinião pública mundial e propiciando a formação de uma frente única em escala mundial, conforme mais tarde seria reconhecido pelo próprio J. Dimitrov (Leibzon, 1975, p. 62). Em entrevista concedida em maio de 1935, dizia ele:

O parlamento alemão.

2 Cf., por exemplo, Correio da Manhã, A Pátria, de 1933, assim como outros jornais. 
Tanto comunistas quanto social-democratas, anarquistas e sem partido, todos se pronunciaram contra o fascismo alemão. Milhões e milhões de operários e operárias, dia após dia, acompanharam a luta em Leipzig. Milhões e milhões de elementos da pequena burguesia, de camponeses, de intelectuais ficaram ao lado da frente única antifascista. ${ }^{3}$

No Brasil, principalmente durante o segundo semestre de 1933, a repercussão do processo de Leipzig e da campanha mundial movida na Europa contra a guerra e o fascismo viria a criar um clima favorável para que, por iniciativa dos comunistas, apoiados em setores da intelectualidade progressista e da opinião pública, fosse formado o Comitê de Luta contra a Guerra Imperialista, a Reação e o Fascismo, que se tornou conhecido como "Comitê Antiguerreiro" (Correio da Manhã, 25 nov. 1933, p. 4; Carone, 1979, p. 247; Carone, 1976, p. 127-128; Roio, 1990, p. 237).

Durante o ano de 1934, com o agravamento da situação econômica do país e o crescimento do movimento grevista ${ }^{4}$, diante do desencanto generalizado com o Governo Vargas - e, principalmente, com os resultados da Constituinte - e devido à agressividade cada vez maior dos integralistas contra o movimento popular e democrático, observa-se uma mobilização impressionante e inédita no Brasil em torno das consignas levantadas inicialmente pelo Comitê Antiguerreiro (Prestes, 1997).

Em 23 de agosto de 1934, realizava-se o $1^{\circ}$ Congresso Nacional contra a Guerra, a Reação e o Fascismo, no teatro João Caetano (RJ), com a presença de cerca de dez mil pessoas. A luta contra a guerra imperialista, a reação e o fascismo - proposta pelos comunistas -, naqueles últimos meses de 1934, conquistava novos setores com uma rapidez impressionante, numa situação em que crescia a ofensiva integralista e a reação policial. O Congresso Antiguerreiro foi dissolvido à bala pela polícia, quando a grande massa que havia comparecido ao ato já se retirava. Houve um saldo de 4 mortos e 20 feridos (Correio da Manhã, 24 ago. 1934, p. 5), fato que provocou intenso repúdio da opinião pública nacional e a deflagração de movimentos grevistas por parte de 40 mil trabalhadores em vários estados do país (Prestes, 1997, p. 57-58).

No início de outubro, no dia 7, um acontecimento de excepcional importância teve lugar em São Paulo: uma manifestação de integralistas na Praça da Sé terminou sendo dissolvida pelas forças

3 A Internacional Comunista, n. 20-21, p. 13 (edição em russo), apud Leibzon (1975, p. 62).

4 Cf. imprensa do ano de 1934; Sampaio (2003). 
antifascistas, reunidas numa primeira ação conjunta (Correio da Manhã, 9 out. 1934, p. 1), para a qual foi decisiva a iniciativa assumida pelo PCB (Partido Comunista do Brasil) de São Paulo, que propôs a formação de uma "Frente Única Antifascista" (Prestes, 1997, p. 58).

Os choques dos antifascistas com os integralistas e as forças policiais tornavam-se cada vez mais violentos, deles resultando mortos, feridos, numerosos presos e muitos deportados. 5 É nesse contexto que se forma a Comissão Jurídica e Popular de Inquérito (CJPI), visando apurar os casos de desaparecimento de militantes antifascistas e de violências praticadas pela polícia e pelos integralistas. Entre os organizadores da Comissão, estavam advogados pertencentes ao PCB ou à Juventude Comunista, ou muito próximos dessas organizações (A Pátria, 11 nov. 1934, p. 3). As adesões que essa entidade recebeu seriam múltiplas e variadas (ibid., nov.dez. 1934).

A partir da documentação disponível, é possível afirmar que a CJPI, contando com a adesão e o apoio do Comitê Antiguerreiro e de diversas outras entidades e frentes que se criaram naquele período, foi a grande aglutinadora das forças que viriam a constituir a maior frente única já formada no Brasil - a Aliança Nacional Libertadora (Prestes, 1997, p. 60-61).

\section{A ANL na legalidade}

Diante da ofensiva reacionária do Governo, que iniciara entendimentos para o envio ao Congresso Nacional do projeto de Lei de Segurança Nacional (significativamente tal projeto ficaria conhecido como "Lei Monstro"), intensifica-se a atuação da CJPI. É no bojo desse crescente movimento pela aglutinação de amplas forças populares e democráticas que nasce a ANL. A mobilização em torno do combate ao projeto da "Lei Monstro" se revela o acontecimento-chave, que precipita, através da intensa atividade pública da CJPI, a criação da ANL. Participam dessa entidade lideranças expressivas da sociedade brasileira: intelectuais de renome, sindicalistas, "tenentes", comunistas, socialistas, entidades democráticas e populares de diferentes colorações ideológicas e políticas.

No ato público de lançamento da ANL, a 30 de março de 1935, Luiz Carlos Prestes é aclamado presidente de honra da entidade, embora ainda não tivesse regressado ao Brasil do exílio onde

5 Cf. A Pátria, números desse período; também outros jornais. 
se encontrava havia vários anos. O "Cavaleiro da Esperança" - que liderara a Coluna Prestes através de 25 mil quilômetros percorridos por todo o território nacional, sem jamais ter sofrido nenhuma derrota no combate movido às tropas governistas -, tornando-se ao final dos anos vinte a mais importante liderança tenentista do país, em 1930 havia rompido com seus antigos companheiros e se recusado a participar do movimento armado, que conduziu Getúlio Vargas ao poder. Prestes denunciara o caráter limitado desse movimento: a disputa pelo poder entre grupos oligárquicos associados aos imperialismos norte-americano e inglês (Prestes, 1997a).

Embora as promessas feitas por Vargas, por ocasião da chamada Revolução de 30, tivessem despertado grandes esperanças em amplos setores da sociedade brasileira, em pouco tempo, o desencanto com o seu governo seria generalizado (Prestes, 1997, cap. 1). Por outro lado, segmentos ponderáveis da opinião pública brasileira voltavam-se cada vez mais para a liderança de Luiz Carlos Prestes, para o programa que ele havia proposto em seu Manifesto de Maio de 1930 e não tinha encontrado eco junto àqueles setores, então iludidos com Vargas e a plataforma da Aliança Liberal (ibid., cap. 2).

A criação da ANL representou a culminância desse processo de aglutinação de grupos, setores, organizações e personalidades decepcionados com o rumo tomado pela Revolução de 30, desiludidos de Vargas e do seu Governo. Ao mesmo tempo, para que essa unidade fosse alcançada, o nome, o prestígio, a liderança de Luiz Carlos Prestes mostraram-se essenciais. Sem o Cavaleiro da Esperança e tudo o que ele representava no Brasil, naquele momento, a ANL dificilmente teria existido.

Naquele ano de 35, a figura de Prestes viria a desempenhar um papel histórico determinado e necessário - congregar em torno da ANL grande parte dos setores da nação insatisfeitos de uma maneira geral com o Governo Vargas e o processo como haviam sido conduzidos os trabalhos da Constituinte e a eleição do presidente da República, mas também com a dominação imperialista do país e a força do latifundismo, com o avanço do integralismo e as medidas antidemocráticas adotadas pelo Governo, como a Lei de Segurança Nacional. O Cavaleiro da Esperança, embora inicialmente distante do país e posteriormente vivendo na clandestinidade, sintetizava em sua figura os anseios de todos esses setores, que, em maio de 30 - quando foi lançado seu famoso Manifesto de rompimento com o tenentismo -, lhe haviam dado as costas. 
Embora não se saiba exatamente de quem foi a iniciativa de fundação da ANL, as informações de que se dispõe e, principalmente, os textos dos pronunciamentos feitos por esta entidade não deixam lugar a dúvidas: a influência das teses defendidas pelo PCB (Partido Comunista do Brasil) é inquestionável. Fato este de fácil verificação, quando se recorre aos documentos da própria ANL. Havia, contudo, nos primeiros documentos dessa entidade uma diferença significativa em relação às posições do PCB, pois a ANL, na fase inicial de sua existência, não levantava a questão do poder, ou seja, de qual seria o governo que deveria implementar suas propostas, consubstanciadas no lema "Pão, Terra e Liberdade" (ibid., cap. 6).

A formação da ANL insere-se no panorama mundial de resistência ao avanço do fascismo e de criação de frentes populares, não só em vários países europeus como também latinoamericanos, bastando lembrar o exemplo do Chile (Caballero, 1987, p. 182-186). No caso brasileiro, a Aliança expressou as insatisfações generalizadas surgidas na sociedade (em particular com os resultados do Governo Vargas), que se concretizaram no programa antiimperialista, antilatifundista e antifascista levantado pelo PCB, com o apoio da Internacional Comunista (IC). A especificidade do movimento consistiu em que, dada a debilidade dos comunistas brasileiros, a adesão de Luiz Carlos Prestes ao PCB e à IC tornou-se um fator decisivo para a penetração e a aceitação desse programa em setores sociais que os comunistas não teriam condições de atingir, particularmente, as camadas médias urbanas, incluindo elementos oriundos do tenentismo e desiludidos com a Revolução de 30 e o Governo Vargas.

A partir da divulgação do seu manifesto-programa, ${ }^{6}$ a $\mathrm{ANL}$ encontraria ampla aceitação, seja nos meios civis (que incluíam tanto setores das camadas médias urbanas quanto do operariado, e mesmo elementos das classes dominantes e das elites políticas) seja junto aos militares de diferentes patentes (oficiais, subalternos e praças). ${ }^{7}$ Como diria anos mais tarde Gregório Bezerra, sargento do Exército que ingressou no PCB e teve papel destacado no Partido e na ANL: "sectário ou não, foi um programa... [o da ANL] [...] que empolgou as massas populares" (Bezerra, 1979, p. 234).

6 "Manifesto da Comissão Provisória de Organização da ANL". In: A Pátria, 1 mar. 1935 , p. 1 e 4.

7 Cf. os jornais citados; Fonseca (1986); Vianna (1992); Konrad (1994). 
Em pouco menos de três meses e meio de vida legal, a ANL chegou a fundar mais de 1.600 núcleos em todo o território nacional, atingindo na capital da República 50 mil inscritos (Sisson, 1937, p. 234), e na cidade de Petrópolis 2.500 aderentes, segundo Roberto Sisson, secretário-geral da entidade (Sisson, 1939, p. 18). Afonso Henriques, secretário do Diretório Municipal do Rio de Janeiro, escreveu que, "segundo cálculos por nós feitos, o quadro social da ANL estava, em maio de 1935, aumentando numa média de 3 mil membros por dia". 8 De acordo com dados fornecidos por Caio Prado Júnior, presidente do Diretório Estadual de São Paulo, a ANL, no momento de seu fechamento, no início de julho de 35, contava nacionalmente com um número de militantes que variava entre 70 e 100 mil, ${ }^{9}$ o que é confirmado por Robert Levine (Levine, 1980, p. 122).

A ANL transformou-se numa grande frente formada tanto através de adesões individuais de destacadas personalidades da cultura, da ciência e da política quanto de organizações populares, sindicais, femininas, juvenis, estudantis, democráticas, etc. Sua composição estava marcada pela presença de setores das camadas médias urbanas, de segmentos do movimento operário e de jovens militares, oriundos em grande parte das lutas tenentistas dos anos vinte.

A direção da ANL contava com a presença de "tenentes", atraídos pela liderança de Prestes, de personalidades progressistas e de militantes do PCB. A presença dos comunistas foi significativa, embora, no início, houvesse restrições de alguns dirigentes do PCB à participação na ANL, pois existia o temor de que o Partido pudesse dissolver-se nessa entidade, conforme se considerava que ocorrera com o Bloco Operário Camponês (BOC), no final dos anos vinte.

A atuação da ANL se caracterizava pela organização de grandes atos públicos, caravanas aos estados do Norte-Nordeste, pela participação em lutas de rua contra os integralistas, pela publicação e vasta distribuição de boletins, volantes e jornais aliancistas. No Rio de Janeiro, A Manhã e, em São Paulo, A Platéa foram os principais jornais que deram publicidade aos documentos e às atividades promovidas pela ANL.

8 Henriques, Afonso.Ascensão e queda de Getúlio Vargas, apud Hernandez (1985, p. 4849).

9 Dados fornecidos a Hernandez (1985, p. 49). 
Embora o programa aliancista despertasse grande entusiasmo junto a setores muito amplos da sociedade brasileira e da opinião pública nacional, não havia na ANL unanimidade nem clareza quanto aos meios a serem empregados para a conquista dos objetivos inscritos nesse programa. Seus primeiros documentos foram omissos nesse particular. ${ }^{10}$ Entre os dirigentes da ANL existia a tendência legalista de considerar possível levar adiante seu programa "dentro da ordem e da lei", posição desde o início criticada pelos comunistas. ${ }^{11}$

$\mathrm{O}$ PCB, mantendo-se fiel à orientação política aprovada em sua Primeira Conferência Nacional, de julho de 1934 (Prestes, 1997, cap. 3), afirmava existir no Brasil uma suposta "situação revolucionária" e convocava os trabalhadores a "pegar em armas desde já", a multiplicar as guerrilhas no campo ${ }^{12}$ e a lutar pela instalação de um "governo operário e camponês, na base de conselhos de operários, camponeses, soldados e marinheiros (sovietes)". ${ }^{13}$ Embora a ANL tivesse adotado o programa antiimperialista, antilatifundista e democrático proposto pelo PCB e amplamente aceito pela opinião pública, devido à influência decisiva de L.C.Prestes, os caminhos para atingir esses objetivos eram vistos de maneiras distintas e contraditórias.

A partir de maio de 1935, sob a influência da Internacional Comunista (à qual estavam filiados todos os partidos comunistas), o PCB viria a adotar a consigna de um Governo Popular Nacional Revolucionário (GPNR), lançada pela primeira vez na carta de Prestes de adesão à ANL, dirigida a H. Cascardo e, por motivos de segurança, datada de Barcelona ${ }^{14}$, ainda que o Cavaleiro da Esperança já estivesse de volta no Brasil.

10 Cf. "1º Manifesto da ANL", lido pelo deputado Gilberto Gabeira na Câmara dos Deputados. In: Diário do Poder Legislativo, RJ, 18 jan. 1935, p. 388-389; "Manifesto da ANL", lançado por intermédio do seu Comitê Provisório de Organização. In: $A$ Pátria, 1 mar. 1935, p. 1 e 4; "Manifesto-relatório da ANL". In: A Pátria, 31 mar. 1935, p. 12.

11 Cf. Rocha, Lauro Reginaldo da (Bangu), "Os perigos do nacional-reformismo na Aliança Nacional Libertadora", A Classe Operária, n. 180, 1 maio 1935. In: Vianna (1995, p. 42).

12 Miranda, "Como os trabalhadores do Brasil resolverão a crise lutando e pegando em armas contra os esfomeadores do Brasil”, A Classe Operária, nº 174, 11 mar. 1935.

13 Miranda, "A luta pela revolução agrária e antiimperialista e a posição do Partido perante a Aliança Nacional Libertadora", A Classe Operária, n. 179, 23 abr. 1935. In: Vianna (1995, p. 36).

14 "Carta de L. C. Prestes a H. Cascardo", Barcelona, 25 abr. 1935. In: Carone (1978, p. 425-430). 
Embora a "carta de Barcelona" fosse datada de 25 de abril, ela só se tornaria conhecida a 13 de maio, quando a ANL realizou no Estádio Brasil, na capital da República, grande ato público alusivo à data da Abolição. Na ocasião, foi lida a carta de Prestes, recebida com grande vibração popular e logo a seguir publicada tanto nos jornais ligados à ANL, quanto na grande imprensa, como, por exemplo, no Correio da Manhã do Rio de Janeiro (Correio da Manhã, 14 maio 1935, p. 1 e 7; A Pátria, 14 maio 1935, p. 1 e 8; A Manhãa, 14 maio 1935, p. 1).

É a partir desse momento que a consigna de um Governo Popular Nacional Revolucionário (GPNR) é adotada oficialmente pela ANL e ganha as ruas. Sua repercussão seria imensa e a aceitação generalizada, embora na carta de Prestes já se falasse em "dar à ANL um caráter antiimperialista combativo e revolucionário", ${ }^{15}$ apontando, portanto, para o caminho da ruptura da legalidade e do apelo à luta armada, o que seria feito logo a seguir pela própria direção da ANL (Prestes, 1997, p. 111).

A influência crescente de Prestes sobre a Aliança, e das teses por ele avalizadas - aprovadas pela direção do PCB na segunda quinzena de maio -, torna-se evidente quando se consulta o documento lançado na mesma época pelo Diretório Nacional da ANL, intitulado "O Governo Popular Nacional Revolucionário e o seu programa". ${ }^{16}$ Dizia-se nesse documento que o GPNR não é o "governo soviético", nem "a ditadura democrática de operários, camponeses, soldados e marinheiros", numa linguagem típica dos comunistas, e acrescentava-se:

Esse governo não será somente um governo de operários e camponeses, mas um governo no qual estejam representada todas as camadas sociais e todas as correntes importantes, ponderáveis da opinião nacional. [...]. À frente de tal governo, como chefe inconteste, com maior prestígio popular em todo o país, não é possível encontrar um nome capaz de substituir o de LUIZ CARLOS PRESTES, porque o nome de Prestes representa para as grandes massas de todo o país a garantia de que tal governo lutará realmente, efetivamente, pela execução do programa da ANL (ibid., p. 1 e 2).

15 Ibid., p. 426; grifo meu.

16 "O Governo Popular Nacional Revolucionário e o seu programa", maio de 1935 (documento datilografado, 5 folhas). Arquivo Getúlio Vargas (AGV). Existem cópias impressas, por exemplo, no processo de Taciano José Fernandes, no Tribunal de Segurança Nacional, caixa 10561, Arquivo Nacional. 
Afirmava ainda a direção da ANL: "O que nós, da ANL, proclamamos é a necessidade de um governo surgido realmente do "povo em armas", esclarecendo a seguir que "o GPNR não significará a liquidação da propriedade privada sobre os meios de produção, nem tomará sob o seu controle as fábricas e empresas nacionais" (ibid., p. 1 e 3; grifos meus).

Surgia, pela primeira vez, nos documentos da ANL, a proposta da luta armada como meio de chegar ao GPNR. A concepção insurrecional do processo revolucionário, adotada tanto pelo PCB quanto pela IC, era assim encampada pela ANL, o que, certamente, não significava que todos os seus dirigentes estivessem com ela de acordo. H. Cascardo, presidente da ANL, comandante da Marinha e "tenente histórico", se manteria fiel às concepções legalistas, externadas por ele desde o momento da criação da ANL, desmentindo, assim, a tese de que a radicalização das posições da ANL e do próprio PCB seria decorrência direta das influências tenentistas, supostamente trazidas por Prestes e os antigos "tenentes" para o movimento.

Durante os meses de maio e junho de 1935, o movimento antifascista no Brasil, sob a direção da ANL, deu consideráveis passos à frente. Repetiam-se as manifestações aliancistas tanto no Rio de Janeiro e em São Paulo quanto nos mais variados pontos do país, destacando-se a cidade fluminense de Petrópolis como um dos lugares onde o movimento adquiriu maior força e onde também ocorreriam choques particularmente violentos com os integralistas. Sob a pressão da campanha liderada pela ANL, os integralistas eram obrigados a recuar, tendo, muitas vezes, suas marchas e manifestações dissolvidas pelas massas mobilizadas pelos diretórios aliancistas. ${ }^{17}$

Ao mesmo tempo, o Governo Vargas, apoiado na "Lei Monstro" e contando com a colaboração da polícia do Distrito Federal, sob o comando do capitão Felinto Müller, intensificava a perseguição não só aos comunistas como aos aliancistas e antifascistas, prendendo e seqüestrando seus líderes, proibindo seus atos públicos e invadindo ou depredando suas sedes e as dos jornais democráticos. Por outro lado, as autoridades policiais fechavam os olhos aos distúrbios promovidos por integralistas, quando não os incentivavam, na busca de pretextos para identificar a ANL com o "comunismo internacional", justificando, assim, a necessidade do seu fechamento. 18

Cf. A Manhã (RJ), A Pátria (RJ), Correio da Manhã (RJ), maio e junho de 1935.

18 Cf. os jornais da época. 
O ambiente político tornava-se visivelmente mais tenso, e era evidente que o Governo se sentia ameaçado pelo avanço do movimento antifascista e os êxitos alcançados pela ANL e demais entidades democráticas e populares, cujo inegável crescimento atraía setores ponderáveis da opinião pública nacional, incluindo uma parte das Forças Armadas.

Enquanto aumentavam a influência e o prestígio da ANL junto aos mais diversos segmentos da opinião pública brasileira, embora seu objetivo programático - "o povo em armas" para conquistar o GPNR - ultrapassasse os limites da legalidade constitucional, as posições dos comunistas sofriam mudanças. Desde o início de abril, a IC insistia junto ao seu Secretariado Sul-Americano e à direção do PCB para que fosse adotada a consigna de "todo o poder à ANL".19 Em telegrama enviado pela Comissão Executiva da IC ao secretário-geral do PCB, o Miranda, era feita a ligação da ANL com o GPNR, deixando claro que, de acordo com a análise da IC, o GPNR deveria ser um poder constituído pela própria ANL, o que, naquele momento, ou seja, antes da reunião do Comitê Central do PCB de maio de 1935, significava a adoção pelos comunistas de uma concepção mais ampla da frente destinada a conquistar o poder. ${ }^{20}$

A consigna de "todo o poder à ANL" foi lançada a 5 de julho, em Manifesto assinado por L. C. Prestes e lido por Carlos Lacerda no ato comemorativo à data dos levantes tenentistas. Se tal Manifesto (Carone, 1978, p. 430-440) revelava, por um lado, a influência da IC na política adotada pelo PCB e a ANL, por outro, expressava a radicalização que vinha se dando no país. Ao intensificar a perseguição movida à ANL e a todas as forças democráticas, o Governo contribuía para que estas se sentissem crescentemente ameaçadas e motivadas a reagirem contra um poder desmoralizado, aparentemente isolado, conivente com os integralistas e empenhado em reprimir os movimentos populares e democráticos. Contudo, os dirigentes da ANL, das demais entidades progressistas e democráticas e do PCB não se davam conta do nível incipiente de organização do movimento aliancista e popular e, desta forma, não percebiam que esse movimento seria incapaz de enfrentar com eficácia o golpe a ser desfechado pelas forças de direita, cuja prepara-

19 Telegrama da IC para o Secretariado Latino-Americano, 29 abr. 1935, em russo. Telegrama da IC "pessoal" a Altobelli (R. Ghioldi), Ferreira (Prestes), Queiroz (Miranda), 7 maio 1935, em alemão. Centro Russo de Conservação e Pesquisa de Documentos de História Contemporânea/AMORJ/IFCS-UFRJ.

20 Telegrama da IC para o C. C. do PCB, camarada Queiroz (Miranda), 13 maio 1935, em alemão.Centro Russo de Conservação... 
ção tornara-se para todos evidente. $\mathrm{O}$ entusiasmo com o crescimento das adesões à ANL, com os comícios extremamente concorridos por ela promovidos, com os movimentos grevistas e as manifestações de insatisfação generalizada de variados setores da vida nacional, levara essas lideranças a superestimarem suas forças e acreditarem que os dias do Governo Vargas estariam contados, sendo viável, pois, a sua derrubada.

Hoje é evidente que a avaliação da situação feita no Manifesto de 5 de julho não correspondia à real correlação de forças presentes no cenário político daquele momento, mas uma parcela considerável e mais radicalizada dos aliancistas não só concordava com tal avaliação como considerava que o apelo de Prestes deveria ser seguido. Assim, explicam-se o entusiasmo com que o documento foi recebido em todo o país e a confiança dos aliancistas em que o chamamento à greve geral, anunciado pela ANL, seria atendido imediatamente pelas massas, caso o Governo decretasse o fechamento da entidade ou resolvesse implantar o estado de sítio. ${ }^{21}$

\section{A ANL na ilegalidade}

A 11 de julho, Getúlio Vargas assinou o decreto fechando a ANL, acusada de ser um instrumento a serviço do "comunismo internacional". 22 Embora o "Manifesto de 5 de Julho" fornecesse um bom pretexto para a adoção dessa medida, sua verdadeira causa residia no fato de que a ANL e as demais entidades democráticas estavam ampliando sua penetração junto à opinião pública e atraindo um número crescente de adeptos e simpatizantes. ${ }^{23} \mathrm{O}$ movimento aliancista adquiria cada vez mais um caráter unitário. Como foi apontado por E. Hobsbawm, a estratégia das "frentes populares", adotada nos anos 30 , pelo movimento comunista internacional, ainda é até hoje aquela mais temida pelas forças da direita, pois a reação sabe que os revolucionários isolados não representam perigo (Hobsbawm, 1991, p. 135). Nada mais temível, pois, do que a sua unidade.

21 Cf. A Pátria, A Manhã, Correio da Manhã, daquele período.

22 Cf. Correio da Manhã, 12 jul. 1935, p. 1. Cf. também: A Pátria, 11 jul. 1935, p.1; 13 jul. 1935, p. 1; A Manhã, 12 jul. 1935, p. 1; 13 jul. 1935, p. 1; e os dias subseqüentes desses jornais.

23 Isso fica evidente ao se consultarem os jornais da época. 
Às vésperas do seu fechamento, a ANL já constituía um perigo para o Governo Vargas, pois em torno do seu programa, respaldado pelo prestígio de Luiz Carlos Prestes, aglutinavam-se setores cada vez mais amplos e heterogêneos da sociedade brasileira. Se a ANL continuasse a ser tolerada na legalidade, poderia transformar-se num pólo aglutinador de forças capazes de, unidas, chegarem a constituir uma ameaça real à estabilidade do regime.

Se essa ameaça, por um lado, era real, por outro, aos aliancistas faltavam organização e capacidade de mobilização dos setores populares - os únicos elementos que lhes poderiam garantir o êxito de seus propósitos. O processo de constituição da ANL enquanto "frente popular" dava apenas os primeiros passos, e a extrema radicalização do seu discurso, com apelos à luta armada, não poderia deixar de alimentar concepções golpistas, ${ }^{24}$ dificultando, apesar de todas as declarações em contrário, o efetivo avanço da organização popular. 25

O fechamento da ANL provocou inúmeros protestos, mas a greve geral, a ser desencadeada em resposta aos repetidos apelos feitos pelos núcleos aliancistas em todo o país, não aconteceu. Houve algumas tentativas em São Paulo, logo abortadas (Correio da Manhã 17 jul. 1935, p. 3). É compreensível que a proibição da ANL não provocasse a reação esperada por alguns de seus dirigentes: na realidade, não havia preparação nem para a greve geral nem para resistir às medidas repressivas desencadeadas com violência pela polícia. As massas que acorriam com entusiasmo aos comícios da ANL não estavam mobilizadas nem organizadas para resistir. Os repetidos chamamentos à greve revelaram-se insuficientes para levá-las a uma efetiva resistência.

Com a proibição oficial da ANL e a violenta repressão desencadeada pelo Governo contra seus militantes e seguidores, era natural que muitos desses elementos, atemorizados e sem ânimo para prosseguir na luta, se afastassem da entidade. Como costuma acontecer em situações similares, de derrota ou de descenso do movimento democrático e progressista, os que permanecem dispostos a persistir no combate pelos objetivos traçados são os mais

24 Chamamos de concepções golpistas ao conjunto de idéias e atitudes, amplamente difundidas na sociedade brasileira, segundo as quais um levante, uma revolta ou um golpe militar poderiam desencadear a insurreição popular. Ainda que os comunistas combatessem o chamado golpismo, na prática não conseguiram resistir à influência das concepções golpistas presentes em nossa sociedade (Prestes, 1997, p. 104, 129-140).

25 Cf. declarações da ANL e do PCB, publicadas em A Manhã, A Pátria, daquele período. 
conscientes e desprendidos, os mais destemidos e conseqüentes. A prática mostrou que esse foi o caso dos comunistas filiados ao PCB. Dispondo de uma estrutura clandestina que lhe conferia condições de assegurar a atividade política de seus militantes nos diretórios aliancistas, o PCB conquistava o controle da entidade, que, a partir do seu fechamento, também se tornara clandestina. Detentores de um grande trunfo político - o nome de Luiz Carlos Prestes -, os comunistas, levados pelas circunstâncias do momento, assumiram na prática a liderança da ANL.

Se os comunistas, antes do fechamento da ANL, já vinham adotando posições de crescente radicalismo, após o decreto de 11 de julho os apelos à luta armada e à insurreição se tornariam mais intensos e freqüentes. Em reunião do Comitê Central do PCB, realizada na segunda quinzena de julho, não só foi reafirmada a orientação aprovada na reunião de maio, mantidas as consignas de GPNR e "todo o poder à ANL", como insistia-se na existência de uma "situação revolucionária" e na necessidade de desencadear tanto lutas grevistas como "lutas armadas e guerrilhas" em nome do GPNR. ${ }^{26}$ Contudo, tomava-se sempre o cuidado de ressaltar a "tarefa primordial de se ligar com as massas" (ibid.) e combater o golpismo. Em documento da ANL, afirmava-se que não se pretendia "tomar o governo por um golpe militar", mas através de "lutas de massa que irão até a insurreição". ${ }^{27}$

Outros exemplos poderiam ser citados. Todos levam à mesma conclusão: as diretivas do PCB e, sob a sua influência, as da ANL, estavam voltadas para o desencadeamento de lutas armadas parciais, que deveriam permitir às massas populares chegarem a uma insurreição nacional. Essa insurreição derrubaria o Governo Vargas, estabelecendo o GPNR com Prestes à frente, ou seja, o poder da ANL, que realizaria os seus objetivos programáticos. Não se tratava, portanto, de uma insurreição para estabelecer o comunismo no Brasil, conforme a História Oficial sempre difundiu, consagrando a designação de "Intentona Comunista" para os levantes de novembro de 1935. Ao mesmo tempo, condenava-se o golpismo, enfatizando-se a necessidade de organizar as massas, preparando-as para a insurreição e a tomada do poder.

26 "Concentremos todas as nossas forças na preparação e desencadeamento das greves, das lutas camponesas e populares". In: Revista Proletária, Rio de Janeiro, n. 5, ago. 1935.

27 "A ANL e a situação política no Estado do RJ" (confidencial). Rio de Janeiro, 3 set. 1935. In: Vianna (1995, p. 89). 
As posições do PCB foram apoiadas e defendidas pelo Secretariado Sul-Americano da IC, o que é confirmado por uma série de telegramas por ele enviado à Comissão Executiva da IC, em Moscou (Prestes, 1997, p. 126). É nesse contexto que deve ser entendida a posição de Prestes, que regressara ao Brasil em abril de 1935, após um exílio de quase dez anos. Correndo o risco de ser preso, seria ele obrigado a viver na clandestinidade, afastado tanto da militância no PCB, de cuja direção não fazia parte, como do contato com os aliancistas e demais correligionários e amigos. Isolado, Prestes acompanhava a situação, seja do movimento popular seja do próprio PCB, através de Miranda - o seu secretário-geral, que lhe transmitia informações exageradas e fantasiosas - e do Secretariado Sul-Americano da IC, cujo conhecimento da real correlação de forças presente na sociedade brasileira naquele momento era precário. Presidente de honra da ANL, Prestes liderava um movimento cujo controle não lhe pertencia.

Mais ainda do que a direção do PCB, Prestes revelaria a preocupação de combater o golpismo. Em cart a Roberto Sisson, de setembro de 1935, ele escrevia: "À diferença dos simples conspiradores, dos golpistas de todos os tempos, nós, os aliancistas, preparamos e marchamos para a insurreição, isto é, a luta de massas, a grande luta em que deve e precisa participar o povo brasileiro". 28

Para deixar mais clara sua posição, Prestes, referindo-se aos violentos acontecimentos ocorridos em Petrópolis, os quais haviam parecido a R. Sisson o sinal de que chegara a hora de pegar em armas, argumentava: Há treze anos que se conspira no Brasil. Mas falta-nos a experiência das verdadeiras lutas insurrecionais, das grandes lutas de massas, das lutas populares conscientemente e cientificamente preparadas" (ibid., p. 19).

E, por isso, enfatizava a importância das "lutas parciais", acrescentando: "Lutas, como a de Petrópolis, precisam ser preparadas e levadas a efeito em todo o Brasil. Depois de uns vinte Petrópolis a insurreição será inevitavelmente vitoriosa" (ibid., p. 20).

De acordo com Prestes, a preparação da insurreição seria longa, pois "vinte Petrópolis" demandariam tempo para serem desencadeados. Tanto os documentos do PCB e do Secretariado SulAmericano da IC quanto os assinados por Prestes deixam clara a preocupação dos comunistas com o perigo representado pelas tradições golpistas, sabidamente presentes na vida política brasileira. Os comunistas insistiam na necessidade de preparar e organizar as

28 "Carta de L. C. Prestes a Roberto Sisson", setembro de 1935. In: Prestes (s.d., p. 1810); grifos meus. 
massas para que a insurreição planejada - uma vez que se postulava a existência de uma "situação revolucionária" no país, num evidente erro de avaliação política - não corresse o risco de transformar-se em mais um golpe militar, como tantos outros antes tentados.

Havia, contudo, uma enorme distância entre os propósitos dos comunistas, enfatizados com tanta insistência em seus documentos, e a avassaladora influência das concepções golpistas, das quais os comunistas não conseguiram escapar.

Durante os meses de outubro e novembro de 1935, o clima de insatisfação generalizada tornara-se particularmente grave no Exército, pois o Governo resolvera implementar com energia a política de redução dos efetivos militares, que vinha sendo planejada havia meses (Prestes, 1997, cap. 7). Numa situação de crescente agitação nos meios operários, quando se intensificava o movimento grevista por todo o país, destacando-se a greve dos ferroviários nordestinos da Great Western (A Manhã, 17 nov. 1935, p. 1 e 8), os comunistas foram levados a concluir que corriam o risco de terem suas bases dentro do Exército solapadas, através das expulsões iniciadas pelo Governo. Desta forma, poderiam perder a oportunidade de desencadear a insurreição armada, cuja preparação "vinha sendo feita desde havia meses", segundo documento do próprio Secretariado Nacional do PCB. 29

O risco era real, pois, como seria assinalado nesse mesmo documento do Partido, a preparação para a insurreição, na região do Rio de Janeiro, "caminhava com bastante lentidão. A preparação de destacamentos civis de combatentes não tinha sido feita [...]", mas "a preparação do setor Militar era melhor e a influência da ANL e do Partido no seio do Exército, entre os oficiais de pequena patente e soldados era decisiva" (ibid., p. 5).

Não é de admirar, pois, que os comunistas, convencidos de que a "desagregação do país" marchava "a passos rápidos, a passos agigantados", ${ }^{30}$ e apostando no Exército como instrumento capaz de desencadear a insurreição popular, decidissem acelerar os preparativos para o seu início. A insurreição estava sendo preparada para dezembro ou janeiro, mas acabou ocorrendo nos últimos dias de novembro, devido à precipitação dos acontecimentos no Nordeste do país. Prestes daria a seguinte explicação:

29 "Situação do movimento revolucionário no Brasil" (documento do Secretariado Nacional do PCB), RJ, 23 maio 1936 (datilografado, 16 folhas). Arquivo do DOPS, setor Administração, pasta 14: 5 (Arquivo do Estado do Rio de Janeiro).

30 "O Grande Exército Popular Nacional" (artigo de L.C. Prestes para O Libertador), s.d. (anterior a 27 nov. 1935), (5 folhas datilografadas). Arquivo do DOPS, setor Comunismo, pasta 9 (Arquivo do Estado do Rio de Janeiro). 
A vida nos colocou frente ao dilema: ir à insurreição com todos os perigos, ou assistir passivos aos acontecimentos do Nordeste e à prisão dos nossos oficiais e expulsão de nossos soldados, aqui no Rio. Cada dia que passasse, mais difícil seria a nossa situação. Perderíamos, sem combate, as mesmas forças que perdemos combatendo. A um revolucionário, a escolha não era difícil. ${ }^{31}$

Não cabendo neste artigo abordar a história dos levantes de novembro, 32 devo assinalar que, segundo os documentos existentes (Prestes, 1997, p. 134-136), a decisão para o seu desencadeamento - diante da precipitação dos acontecimentos no Nordeste - foi tomada pela direção do PCB conjuntamente com o Secretariado Sul-Americano da IC; o que restara da ANL, confinada na ilegalidade, encontrava-se sob a direção dos comunistas. Os levantes de novembro não resultaram, portanto, de supostas "ordens de Moscou", conforme as versões consagradas pela História Oficial.

\section{Algumas conclusões}

Num período de intensa polarização política no cenário mundial, diante do avanço do fascismo em nível internacional e do integralismo em âmbito nacional, a ANL desempenhou um papel decisivo na mobilização de amplos segmentos da sociedade e da opinião pública brasileira em defesa das liberdades públicas, gravemente ameaçadas pelos adeptos da Ação Integralista Brasileira, liderados por Plínio Salgado. A ANL promoveu grandes atos e manifestações contra o integralismo, contribuindo tanto para o desmascaramento do seu caráter antinacional e antidemocrático como para o seu crescente isolamento.

A ANL ajudou a formar, no Brasil, uma consciência antifascista, antiimperialista e antilatifundista, que a derrota de novembro de 35 não seria capaz de apagar. Consciência que viria a renascer no início dos anos quarenta, com o movimento pela entrada do Brasil na guerra contra o nazifascismo, ao lado da URSS e das potências aliadas.

31 "Carta de Prestes de dezembro de 1935" (rascunho). In: Vianna (1995, p. 378).

32 Cf., por exemplo, Silva (1969), Carone (1976), Levine (1980), Canale (1985), Hernandez (1985), Fonseca (1986), Sodré (1986), Roio (1990), Pinheiro (1991), Vianna (1992), Costa (1995). 
A conjugação da luta contra o fascismo e o integralismo com o combate ao imperialismo e ao latifundismo era justa, uma vez que o fascismo e o seu congênere nacional podem ser caracterizados como fenômenos associados, em determinadas circunstâncias, ao capital monopolista e financeiro (Gramsci, 1970, p. 101; Dimitrov, 1969, p. 117). Ao mesmo tempo, o capital estrangeiro, no Brasil, sempre se mostrou solidário com a manutenção do monopólio da terra, tendo seus interesses entrelaçados com os das oligarquias agrárias.

Os comunistas cometeram, entretanto, um erro de avaliação ao caracterizarem a situação do país como "revolucionária", considerando que o desgaste do Governo Vargas seria tal que as suas condições de governabilidade estariam esgotadas. Confundindo os desejos com a realidade, os comunistas e muitos dos seus aliados superestimaram as possibilidades reais de organização e mobilização das massas populares. Consideraram que havia chegado a hora de levantar a questão do poder, lançando a diretiva de um Governo Popular Nacional Revolucionário, formado pela ANL, através de uma insurreição popular. A proposta dos comunistas, assumida pela ANL, mostrou-se fantasiosa e, portanto, inexeqüível, resultando na derrota do movimento.

A inviabilidade de promover uma insurreição das massas trabalhadoras no Brasil, em 1935, induziu os comunistas e seus aliados da ANL a sucumbirem à influência das concepções golpistas, fortemente arraigadas no imaginário nacional. Tal fenômeno sobreveio, apesar dos esforços desenvolvidos para organizar e mobilizar as massas, assim como das repetidas e insistentes declarações do PCB, de Prestes e da ANL condenando o golpismo. A conjuntura de intensa agitação e efervescência política então presente nas Forças Armadas foi um fator de grande importância para que esse novo surto de golpismo viesse a contagiar as "esquerdas" brasileiras.

$O$ revés sofrido pelo movimento antifascista no Brasil, em 1935, não se explica, contudo, apenas pela influência das concepções golpistas. O Governo Vargas, não obstante o desgaste que vinha sofrendo junto a diferentes setores sociais, pôde tirar partido de uma conjuntura internacional favorável ao avanço do fascismo e ao estabelecimento de regimes autoritários para, com o apoio da direita e brandindo as bandeiras do anticomunismo, impor uma grave derrota às forças democráticas e progressistas do país. 


\section{Referências}

BEZERRA, Gregório. Memórias (1ª parte: 1900-1945). Rio de Janeiro: Civilização Brasileira, 1979.

CABALLERO, Manuel. La Internacional Comunista y la revolución latinoamericana, 1919-1943. Caracas: Nueva Sociedad, 1987.

CANALE, Dario. A Internacional Comunista e o Brasil (1920-1935). In: TAVARES, José Nilo (org.). Novembro de 1935: meio século depois. Petrópolis: Vozes, 1985.

CARONE, Edgard. A República Nova (1930-1937). 2. ed. São Paulo: Difel, 1976. . A Segunda República (1930-1937). 3. ed. São Paulo: Difel, 1978.

. Movimento Operário no Brasil (1877-1944). São Paulo: Difel, 1979.

COSTA, Homero de Oliveira. A Insurreição Comunista de 1935: Natal, o primeiro ato da tragédia. São Paulo/Rio Grande do Norte: Ensaio/Cooperativa Cultural Universidade do Rio Grande do Norte, 1995.

DIMITROV, George. La ofensiva del fascismo y las tareas de la Internacional Comunista en la lucha por la unidad de la clase obrera. Informe apresentado no VII Congresso Mundial da 3a IC (2/8/35). In: El Frente Único y Popular. Sofia: Sofia-Press, 1969, p. 116-197.

FONSECA, Vitor Manoel da. A ANL na legalidade. Niterói: UFF, 1986 (Dissertação de Mestrado em História).

GRAMSCI, Antonio. Opere. Socialismo e Fascismo (L'Ordine Nuovo, 1919-1920). Torino: Einaudi, 1970.

HERNANDEZ, Leila M. G. A Aliança Nacional Libertadora: ideologia e ação. Porto Alegre: Mercado Aberto, 1985.

HOBSBAWM, Eric J. Estratégias para uma Esquerda Racional: escritos políticos 1977-1988. Rio de Janeiro: Paz e Terra, 1991.

. A era dos extremos: o breve século XX (1914 -1991). São Paulo: Companhia das Letras, 1995.

KONRAD, Diorge Alceno. 1935: a Aliança Nacional Libertadora no Rio Grande do Sul. Porto Alegre: PUCRS, 1994 (Dissertação de Mestrado em História).

LEIBZON, B. M.; SCHIRINIÁ, K. K. A virada na política do Komintern: o significado histórico do VII Congresso do Komintern. Moscou: Misl, 1975 (Edição original em russo.)

LEVINE, Robert M. O Regime de Vargas, 1934-1938: os anos críticos. Rio de Janeiro: Nova Fronteira, 1980.

PINHEIRO, Paulo Sérgio. Estratégias da ilusão: a Revolução Mundial e o Brasil, 1922-1935. São Paulo: Comp. das Letras, 1991.

PRESTES, Anita Leocadia. Luiz Carlos Prestes e a Aliança Nacional Libertadora: os caminhos da luta antifascista no Brasil (1934/35). Petrópolis: Vozes, 1997. 
. A Coluna Prestes. 4. ed. São Paulo: Paz e Terra, 1997a.

PRESTES, Luiz Carlos. Problemas atuais da democracia. Rio de Janeiro: Vitória, s.d.

ROIO, Marcos Del. A classe operária na revolução burguesa: a política de alianças do PCB: 1928-1935. Belo Horizonte: Oficina de Livros, 1990.

SAMPAIO, Karine Dull. A luta do movimento operário no Rio de Janeiro e sua relação com o PCB nos anos 1934 e 1935. Rio de Janeiro: PPGHS/IFCS/UFRJ, 2003 (Dissertação de Mestrado em História).

SILVA, Hélio. 1935 - a Revolta Vermelha. Rio de Janeiro: Civilização Brasileira, 1969.

SISSON, Roberto. Carta Aberta à Marinha de Guerra. Rio de Janeiro: Rodrigues \& C., 1937.

. La Revolución Democratica Progresista Brasileña. Buenos Aires: RioBuenos Aires, 1939.

SODRÉ, Nelson Werneck. A Intentona Comunista de 1935. Porto Alegre: Mercado Aberto, 1986.

VIANNA, Marly de Almeida Gomes. Revolucionários de 35: sonho e realidade. São Paulo: Companhia das Letras, 1992.

. (org.). Pão, terra e liberdade: memória do movimento comunista de 1935. Rio de Janeiro/São Carlos: Arquivo Nacional/Universidade Federal de São Carlos, 1995. 